\title{
Electroencephalographic studies on petrol intoxication: comparison between nonleaded and leaded white petrol
}

\author{
KAZUO SAITO \\ Department of Hygiene and Preventive Medicine, \\ Hokkaido University School of Medicine, Sapporo, Japan
}

\begin{abstract}
Saito, K. (1973). British Journal of Industrial Medicine, 30, 352-358. Electroencephalographic studies on petrol intoxication: comparison between nonleaded and leaded white petrol. The effect of nonleaded and leaded petrol on the brains of rats was studied electroencephalographically. Bipolar electrodes were implanted on the brain surface between the frontal and occipital lobes of the left hemisphere. The rats were divided into two groups and were given by intraperitoneal injection $1 \mathrm{ml}$ of either nonleaded white petrol (WP) or leaded petrol (LP) containing $1000 \mathrm{ppm}$ of tetraethyl lead per $100 \mathrm{~g}$ body weight. The electrocorticogram was observed for 10 days and the lead content of the brain, liver, and kidney was estimated.

The rats injected with leaded petrol showed excessive tension and excitement by the sixth or seventh day, and their body weight had diminished significantly by 10 days. One to three days after both LP and WP injection, the $\delta, \theta$, and $\alpha$ waves decreased significantly but the electrocorticogram from six or seven days after LP injection showed marked $\alpha$ and $\theta$ waves. The lead content in organs of the LP group was far greater than in those of the WP group and a correlation between the electrocorticogram and lead content was recognized.
\end{abstract}

The composition of petrol presents an important problem because of air pollution due to lead and photochemical substances contained in exhaust gases from motor vehicles (Hirschler and Gilbert, 1964; Konopinski and Upham, 1967; Colucci, Begeman, and Kumler, 1969; Kobayashi, Hori, and Tsuchiya, 1970; Pierrard, 1972). Their effects on the population (Hofreuter, Catcott, Keenan, and Xintaras, 1961; Hyuga et al., 1970) have become a serious matter. We have previously reported on the toxicity and lead content of commercially available regular petrol and high octane petrol in relation to the survival rate of rats and their electrocorticograms (ECoG) (Saito, Inai, and Takakuwa, 1972). Petrol is largely composed of $n$-heptane and $n$-hexane and contains more than 10 kinds of hydrocarbons such as n-octane, $\mathrm{n}$-decane, toluene, and xylene. Its toxicity is, therefore, complicated by this composition and the mixing rate of alkyl lead. Tetraethyl lead is a liquid and is fat-soluble; it is therefore much more toxic than inorganic lead. We have experienced this intoxication in Japan (Asada, 1953; Yamaga et al., 1959). Although the toxicity of tetraethyl lead per se is not a general environmental problem, it is very important for us, who specialize in environmental health, to be familiar with the toxicity of tetraethyl lead and petrol.

In this experiment a comparison was made between 
the toxicity of white petrol with and without added tetraethyl lead.

\section{Materials and methods}

The skulls of 19 white male Wistar rats, weighing 330 to $453 \mathrm{~g}$ and aged 7 months, were drilled under Nembutalether anaesthesia about $3 \mathrm{~mm}$ from the left side of the sagittal suture at points $1.5 \mathrm{~mm}$ above and below the coronary suture. Bipolar electrodes, having a small socket for a transistor and with a silver globular tip $0.7 \mathrm{~mm}$ in diameter to protect the cortex from injury, were implanted on the surface of the brain about $3 \mathrm{~mm}$ apart over the frontal and occipital lobes of the left hemisphere. The electrodes were attached on the skull permanently with dental cement. The rats were divided into two groups, one containing 12 rats and the other seven. The former group was given white petrol only (WP) and the latter group white petrol containing $1000 \mathrm{ppm}$ lead (LP); in both groups the petrol was injected into the abdominal cavity in a dose of $1 \mathrm{ml} / 100 \mathrm{~g}$ body weight. The tetraethyl lead content of the petrol (LP) was $1.0 \mathrm{ml} / \mathrm{l}$, that is, $16.5 \mathrm{mg} / \mathrm{kg}$ body weight of rat. The $L D_{50}$ value for tetraethyl lead is 13.2 to $18.0 \mathrm{mg}$ / kg (Cremer, 1965).

The observations were made one month after recovery from the implant operation. The ECoG was recorded one day before and $1,2,3,4,5,7$, and 10 days after injection respectively. It was measured under normal conditions in an electrically shielded chamber with a 13-channel electroencephalograph and ECoG frequency analyzer (Nihon Kohden Model ME 132B and 4B). The primary trace, the ongoing activity in the ECoG ( $\delta$ wave $2-4 \mathrm{~Hz}, \theta$ wave $4-8 \mathrm{~Hz}$, $\alpha$ wave $8-13 \mathrm{~Hz}, \beta_{1}$ wave $13-20 \mathrm{~Hz}$, $\beta_{2}$ wave $20-30 \mathrm{~Hz}$ ), and each 10 -second integral value of these waves were averaged for 5 to 10 minutes of a recording.

At the end of a 10-day experimental period, the rats were decapitated, and it was confirmed histologically that the electrodes were on the surface of the cortex. At the same time the brain, liver, and kidney were taken out. Lead contained in these organs was extracted with APDC MIBK after wet-ashing with sulphuric and nitric acids and determined by atomic absorption spectrophotometry (Hitachi Model 207).

\section{Results}

\section{Clinical symptoms}

The rats in the electrically shielded chamber before administration of petrol were restless at first, walked up and down the length of the chamber, and tried to rub off the lead wires fitted on the head and to climb up the side wall of the chamber. In about 10 minutes they settled down, and the ECoG was recorded without fluctuation. One to four days after petrol injection the rats showed slowing of movements, a crouching posture, and absence of reaction to stimuli. Walking movements appeared from five days after injection. One to four days after petrol injection behaviour such as crouching was more noticeable in the LP group than in the WP group.
After the fifth day from petrol injection, the rats in the WP group gradually approached their preinjection state, but the rats in the LP group showed excessive tension, excitement, anxiety, and sensitivity to stimuli such as sudden noise and movement. These abnormal states reached a climax at seven or eight days after LP injection. After the tenth day from injection, the rats quietened down from excitement.

\section{Changes in body weight}

The body weights of the rats in both groups before petrol injection are shown in Table 1. The average

TABLE 1

Changes of Body Weight (Grammes) in Rats

INJeCted With Nonleaded Petrol (WP) AND Leaded PeTrol (LP)

\begin{tabular}{ll|c|c|c}
\hline & $\begin{array}{c}\text { Before } \\
\text { injection }\end{array}$ & $\begin{array}{c}10 \text { days } \\
\text { after injection }\end{array}$ & Difference \\
\hline WG & $\cdots$ & $389 \cdot 4 \pm 13 \cdot 5$ & $351 \cdot 8 \pm 10 \cdot 8^{1}$ & $-37 \cdot 6 \pm 3 \cdot 5^{3}$ \\
LG & $\cdots$ & $396 \cdot 4 \pm 13 \cdot 1$ & $298 \cdot 0 \pm 24 \cdot 3^{2}$ & $-98 \cdot 4 \pm 15 \cdot 5^{3}$ \\
\hline
\end{tabular}

Mean \pm SE ${ }^{1}$ Change significant at $10 \%$ level

${ }^{2}$ Change significant at $5 \%$ level

${ }^{3}$ Change significant at $1 \%$ level

body weight of the WP group before injection was $389.4 \mathrm{~g}$ and that of the LP group $396.4 \mathrm{~g}$. The body weight 10 days after petrol injection was $351.8 \mathrm{~g}$ in the WP group and 298.0 $\mathrm{g}$ in the LP group. The body weights of both groups decreased significantly compared to their original weights. Decrease of body weight in the LP group was more significant compared to that in the WP group.

\section{ECoG before and after petrol injection}

The control ECoG before injection showed a dominant $\theta$ wave and marked $\alpha$ and $\delta$ waves, and the amplitudes of these waves ranged from 50 to 150 microvolts. An ECoG after WP injection showed decreases in the $\delta, \theta, \alpha$, and $\beta_{1}$ waves. The $\beta_{2}$ wave was inclined to increase, and the rats showed a state of slow motion and a crouching posture at this time. The $\alpha$ waves of rats in the LP group increased markedly and dominantly seven days after LP injection (Fig. 1). At this time the rats showed excessive excitement and tension. This progression is shown in Tables 2 and $\mathbf{3}$ and in Figure 2. In comparison with the control ECoG, only the $\alpha$ wave decreased significantly one, two, and three days after WP injection $(P<0.05)$, but from four days after WP injection no significant changes were shown. One to three days after LP injection there was a significant decrease of the $\delta$ and 

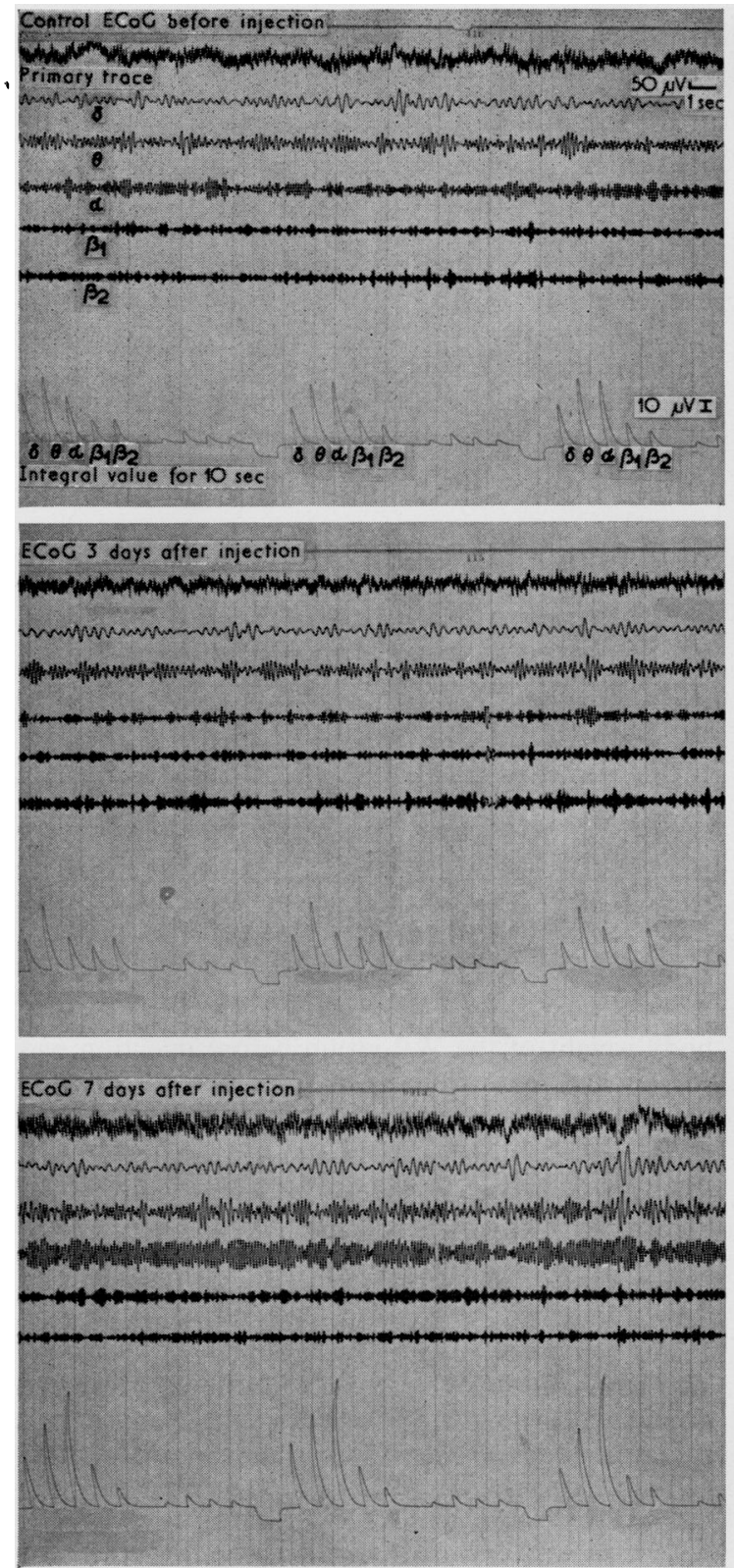
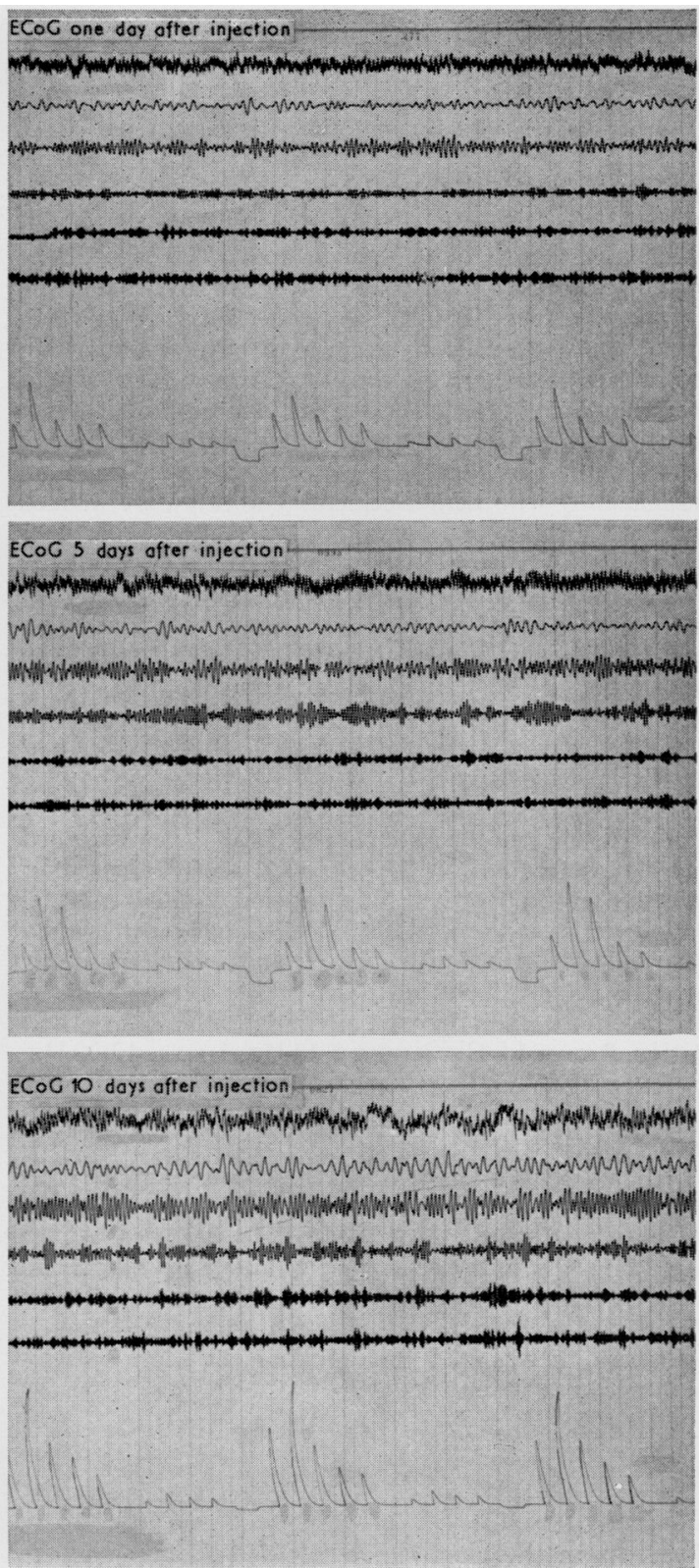

FIG. 1. ECoG changes in rats injected with leaded petrol (LP); before injection and 1, 3, 5, 7, and 10 days after injection: primary trace, ongoing activities of $\delta, \theta, \alpha, \beta_{1}, \beta_{2}$, and the integral values for 10 seconds.

$\theta$ waves as well as a significant increase of the $\alpha$ wave at seven days and the $\theta$ wave at 10 days after LP injection $(\mathbf{P}<0.05)$. Significant differences were observed when changes of these waves in the WP group were compared with those in the LP group $(P<0.05)$. At 10 days after $L P$ injection only the $\theta$ wave showed a significant change.
Amount of lead in organs and its correlation with the ECoG

The amounts of lead in the brain, liver, and kidney 10 days after WP injection and 10 days after LP injection are shown in Figure 3. The average values and standard errors in microgrammes per gramme wet weight of the WP group 10 days after injection 

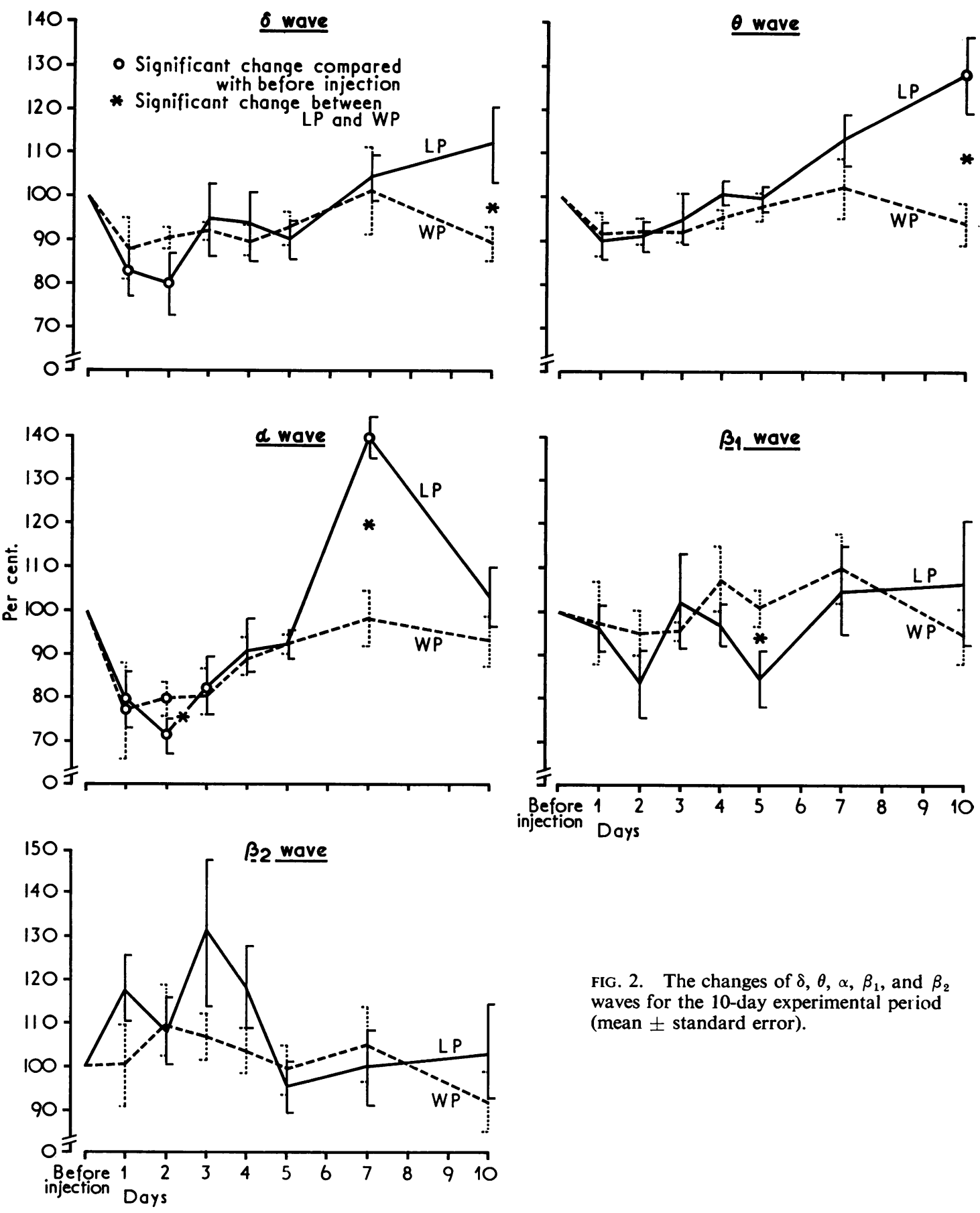

FIG. 2. The changes of $\delta, \theta, \alpha, \beta_{1}$, and $\beta_{2}$ waves for the 10-day experimental period (mean \pm standard error).

were $0.35 \pm 0.06$ in the brain, $0.54 \pm 0.22$ in the liver, and $0.38 \pm 0.12$ in the kidney. Those of the LP group were $7.65 \pm 0.78$ in the brain, $7.79 \pm 1.04$ in the liver, $13.89 \pm 2.40$ in the kidney, and
$12.67 \pm 1.91$ in the blood. The amount of lead in the organs of the WP group was smaller than that of the LP group. 
TABLE 2

Average Integral Values of ECoG $(\mu \mathrm{v} / 10$ SEC) in Rats InJeCted with $1 \mathrm{~mL} / 100 \mathrm{~g}$ Body Weight of Nonleaded Petrol

\begin{tabular}{|c|c|c|c|c|c|c|c|c|c|c|c|}
\hline & & & & \multirow{2}{*}{$\begin{array}{c}\text { Before } \\
\text { injection }\end{array}$} & \multicolumn{7}{|c|}{ Day after injection } \\
\hline & & & & & 1 & 2 & 3 & 4 & 5 & 7 & 10 \\
\hline \multirow{2}{*}{$\delta$} & & & Mean & $64 \cdot 6$ & $56 \cdot 6$ & $58 \cdot 3$ & $59 \cdot 5$ & $57 \cdot 7$ & $59 \cdot 8$ & $65 \cdot 5$ & $57 \cdot 8$ \\
\hline & $\cdots$ & $\cdots$ & SE & $5 \cdot 8$ & $5 \cdot 0$ & $4 \cdot 8$ & $5 \cdot 1$ & $4 \cdot 5$ & $4 \cdot 6$ & 5.9 & $4 \cdot 2$ \\
\hline \multirow{2}{*}{$\theta$} & & & Mean & $81 \cdot 9$ & $74 \cdot 7$ & $75 \cdot 3$ & $75 \cdot 3$ & $78 \cdot 0$ & $80 \cdot 0$ & $83 \cdot 8$ & $76 \cdot 8$ \\
\hline & $\cdots$ & $\cdots$ & SE & $7 \cdot 7$ & $7 \cdot 2$ & $7 \cdot 5$ & $7 \cdot 3$ & $6 \cdot 0$ & $6 \cdot 4$ & $7 \cdot 3$ & $6 \cdot 3$ \\
\hline \multirow{2}{*}{$\alpha$} & & & Mean & $58 \cdot 3$ & $44 \cdot 9^{1}$ & $46 \cdot 3^{1}$ & $46 \cdot 9$ & $51 \cdot 6$ & 53.6 & $57 \cdot 3$ & $54 \cdot 2$ \\
\hline & $\cdots$ & $\cdots$ & SE & $5 \cdot 4$ & 3.9 & 3.6 & $4 \cdot 1$ & $4 \cdot 0$ & $5 \cdot 1$ & 5.0 & $4 \cdot 8$ \\
\hline \multirow{2}{*}{$\beta_{1}$} & & & Mean & 40.9 & 39.9 & 38.7 & $39 \cdot 0$ & $43 \cdot 8$ & $41 \cdot 1$ & $44 \cdot 9$ & $38 \cdot 3$ \\
\hline & $\cdots$ & $\cdots$ & SE & $4 \cdot 1$ & $3 \cdot 2$ & $3 \cdot 3$ & $3 \cdot 3$ & 4.9 & 5.0 & $4 \cdot 5$ & $4 \cdot 6$ \\
\hline \multirow{2}{*}{$\beta_{2}$} & & & Mean & $41 \cdot 9$ & $42 \cdot 1$ & 45.9 & 44.9 & 43.6 & $41 \cdot 8$ & $44 \cdot 1$ & $38 \cdot 5$ \\
\hline & & & SE & $4 \cdot 1$ & $4 \cdot 6$ & $5 \cdot 1$ & $4 \cdot 3$ & $4 \cdot 6$ & 4.9 & $4 \cdot 2$ & $5 \cdot 0$ \\
\hline \multicolumn{3}{|c|}{ No. of samples } & & 7 & 7 & 7 & 7 & 7 & 7 & 7 & 7 \\
\hline
\end{tabular}

${ }^{1}$ Change significant compared to value before injection at $10 \%$ level.

TABLE 3

Average INTEgral Values of ECoG $(\mu \mathrm{v} / 10$ SeC) INJeCted With $1 \mathrm{ML} / 100 \mathrm{~g}$ Body Weight of Leaded Petrol

\begin{tabular}{|c|c|c|c|c|c|c|c|c|c|c|c|}
\hline & & & & \multirow{2}{*}{$\begin{array}{c}\text { Before } \\
\text { injection }\end{array}$} & \multicolumn{7}{|c|}{ Day after injection } \\
\hline & & & & & 1 & 2 & 3 & 4 & 5 & 7 & 10 \\
\hline \multirow{2}{*}{$\delta$} & \multirow{2}{*}{. } & \multirow{2}{*}{. } & Mean & $57 \cdot 6$ & $47 \cdot 8^{3}$ & $46 \cdot 2^{2}$ & $54 \cdot 6$ & $54 \cdot 0$ & $51 \cdot 8$ & $60 \cdot 0$ & $64 \cdot 5$ \\
\hline & & & SE & $3 \cdot 5$ & $4 \cdot 2$ & $3 \cdot 6$ & $4 \cdot 9$ & $4 \cdot 7$ & $4 \cdot 1$ & $4 \cdot 0$ & $4 \cdot 0$ \\
\hline \multirow{2}{*}{$\theta$} & \multirow{2}{*}{. } & \multirow{2}{*}{. } & Mean & $79 \cdot 9$ & $72 \cdot 1$ & $73 \cdot 0$ & $75 \cdot 9$ & $80 \cdot 5$ & $79 \cdot 8$ & $90 \cdot 5$ & $102 \cdot 5^{2}$ \\
\hline & & & SE & $5 \cdot 7$ & $6 \cdot 0$ & $5 \cdot 2$ & $4 \cdot 7$ & $5 \cdot 8$ & $5 \cdot 4$ & $3 \cdot 8$ & $7 \cdot 3$ \\
\hline \multirow{2}{*}{$\alpha$} & \multirow{2}{*}{$\cdots$} & \multirow{2}{*}{$\cdots$} & Mean & $57 \cdot 0$ & $45 \cdot 2^{3}$ & $40 \cdot 6^{1}$ & $46 \cdot 5^{3}$ & $51 \cdot 8$ & $52 \cdot 7$ & $79 \cdot 4^{3}$ & $60 \cdot 6$ \\
\hline & & & SE & $4 \cdot 0$ & $5 \cdot 0$ & $3 \cdot 1$ & $4 \cdot 3$ & $6 \cdot 2$ & $4 \cdot 9$ & $11 \cdot 1$ & $5 \cdot 2$ \\
\hline \multirow{2}{*}{$\beta_{1}$} & \multirow{2}{*}{. } & \multirow{2}{*}{. } & Mean & $33 \cdot 3$ & $32 \cdot 0$ & $27 \cdot 6$ & $34 \cdot 0$ & $32 \cdot 3$ & $28 \cdot 1$ & $34 \cdot 7$ & $35 \cdot 5$ \\
\hline & & & SE & $4 \cdot 2$ & $5 \cdot 4$ & $2 \cdot 4$ & $4 \cdot 5$ & $4 \cdot 5$ & $2 \cdot 7$ & $2 \cdot 5$ & $3 \cdot 5$ \\
\hline \multirow{2}{*}{$\beta_{2}$} & \multirow{2}{*}{. } & \multirow{2}{*}{. } & Mean & $27 \cdot 2$ & $32 \cdot 0$ & $29 \cdot 4$ & 35.9 & $32 \cdot 1$ & $26 \cdot 1$ & $27 \cdot 2$ & $28 \cdot 1$ \\
\hline & & & SE & $3 \cdot 8$ & $5 \cdot 3$ & $4 \cdot 1$ & $6 \cdot 0$ & $5 \cdot 1$ & $3 \cdot 4$ & $2 \cdot 8$ & $3 \cdot 3$ \\
\hline \multicolumn{4}{|c|}{ No. of samples } & 12 & 12 & 12 & 11 & 12 & 12 & 11 & 10 \\
\hline
\end{tabular}

${ }^{1}$ Change significant compared to value before injection at $1 \%$ level

${ }^{2}$ Change significant compared to value before injection at $5 \%$ level

${ }^{3}$ Change significant compared to value before injection at $10 \%$ level 


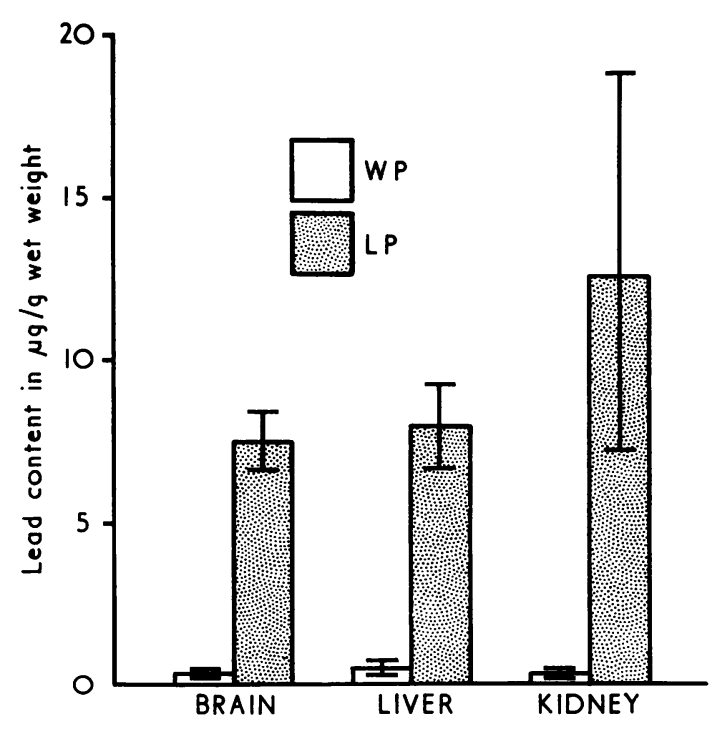

FIG. 3. Lead content of rats $\mathbf{1 0}$ days after intraperitoneal injection of petrol: WP $=$ nonleaded petrol $; \mathrm{LP}=$ leaded petrol.

\section{Discussion}

The acute toxic symptoms caused by absorption of petrol are headache, dizziness, delusions, drowsiness, anxiety, excitement, staring, delirium, diminution of tendon reflexes, tremor, faintness, nausea, vomiting, abdominal pain, foaming at the mouth, lowering of body temperature, chilliness of the skin, cyanosis, etc. (Patty, 1963). The symptoms of tetraethyl lead poisoning are insomnia, lack of appetite, nausea, vomiting, irritability, restlessness, nervousness, anxiety, tiredness, excessive dreaming, emotional instability, hallucinations, excitement, delirium, etc. (Cassells and Dodds, 1946; Cremer, 1959; Sanders, 1964). We have previously reported the effect of commercially available regular petrol and high octane petrol on rats and indicated that the toxicity of these petrols was greater than that of nonleaded white petrol, and that these results suggested that the toxicity of petrol was greatly complicated by various combinations of three factors-the quantity and quality of the petrol, and the alkyl lead added to it. Almost all of the rats injected with regular petrol and high octane petrol died with acute poisoning in the previous experiment (Saito et al., 1972), but in the present experiment almost none of the rats injected with LP died during the same 10-day experimental period. The most characteristic clinical symptoms of the LP group of rats in this experiment were excessive tension and excitement, anxiety, and sensitivity to stimuli, as also reported by Cremer (1965). In the previous experiment (Saito et al.,
1972) the rats injected with regular petrol and high octane petrol showed nystagmus and convulsions of the extremities about two or three days after injection but almost all died three to five days after injection. The dominant basic pattern of the ECoG before injection, especially the $\delta, \theta$ and $\alpha$ waves, significantly decreased one to three days after LP injection, and the rats showed loss of appetite, no desire for water, ataxia, drowsiness, dullness, crouching, and a lowered body temperature. The diminution of basic pattern and these clinically severe symptoms in the LP group were significantly more pronounced than those in the WP group. From about the sixth or seventh day afer injection the rats of the LP group showed excessive tension and excitement but the rats in the WP group did not show such symptcms and approached the control state. These results also indicate that the acute toxicity of LP is greater than that of WP.

The ECoG during excessive tension and excitement from the sixth or seventh day after LP injection showed a remarkable increase of the $\alpha$ and $\theta$ waves. The lead content of the brain, liver, and kidney five days after LP injection was about two to four times that at 10 days after injection (Saito, 1972). Walker and Boyd (1952) and Ermakov and Murashov (1969) reported on the ECoG of a patient poisoned by tetraethyl lead, but they did not suggest by what mechanism the changes in the ECoG were brought about. We suggest that the striking increase of $\alpha$ and $\theta$ waves is due to a direct action of triethyl lead, particularly on the brain stem reticular formation. It is known that tetraethyl lead is converted to triethyl lead by the liver and that the triethyl lead enters the brain (Cremer, 1959; Hayakawa, 1972). Whether the changes in electrical activity are a consequence of metabolic disturbances, such as those described by Cremer $(1959,1964,1965)$ on glucose and amino acid metabolism, or whether they are due to a direct action on nerve membranes remains unanswered.

The author would like to thank Mr. S. Ishimura for technical assistance.

\section{References}

Asada, Y. (1953). A case of tetraethyl lead poisoning in those who treated gasoline. Journal of Kyoto Medical Association, 4, 29-31.

Cassells, D. A. K., and Dodds, E. C. (1946). Tetra-ethyl lead poisoning. British Medical Journal, 2, 681-685.

Colucci, J. M., Begeman, C. R., and Kumler, K. (1969).

Lead concentrations in Detroit, New York, and Los Angeles air. Journal of the Air Pollution Control Association, 19, 255-260.

Cremer, J. E. (1959). Biochemical studies on the toxicity of tetraethyl lead and other organo-lead compounds. British Journal of Industrial Medicine, 16, 191-199.

- (1964). Amino acid metabolism in rat brain studied with ${ }^{14}$ C-labelled glucose. Journal of Neurochemistry, 11, 165-185. 
(1965). Toxicology and biochemistry of alkyl lead compounds. Occupational Health Review, 17, No. 3, pp. 14-19.

Ermakov, E. V., and Murashov, B. F. (1969). On the mechanism of tetraethyl lead action. Gigiena Truda i Professional' nye Zabolebaniya, 13, No. 7, pp. 53-54. (In Russian).

Hayakawa, K. (1972). Microdetermination and dynamic aspects of in vivo alkyl lead compounds. Part II. Studies on the dynamic aspects of alkyl lead compounds in vivo. Japanese Journal of Hygiene, 26, 526-535.

Hirschler, D. A., and Gilbert, L. F. (1964). Nature of lead in automobile exhaust gas. Archives of Environmental Health, 8, 297-313.

Hofreuter, D. H., Catcott, E. J., Keenan, R. G., and Xintaras, C. (1961). The public health significance of atmospheric lead. Archives of Environmental Health, 3, 568-574.

Hyuga, M., Nakagawa, K., Hattori, O., Yagyu, H., Oyagi, S., Takehuta, S., and Seki, Y. (1970). The effect of lead in air on the population. Japanese Journal of Public Health, 17, 785.

Kobayashi, Y., Hori, M., and Tsuchiya, K. (1970). Horizontal and perpendicular distribution of lead particulates in air around a busy road in Yokohama city. Japanese Journal of Public Health, 17, 307-312.

Konopinski, V. J., and Upham, J. B. (1967). Commuter exposure to atmospheric lead. Archives of Environmental Health, 14, 589-593.

Patty, F. A. (Editor) (1963). Industrial Hygiene and Toxicology, 2nd edition, Vol. 2, pp. 1199-1217. Interscience Publishers, Wiley, New York/London.

Pierrard, J. M. (1972). Visibility and soiling: a comparison of the effects of leaded and unleaded gasolines. Science, 175, 516-518.

Saito, K. (1972). Unpublished data.

-, Inai, H., and Takakuwa, E. (1972). Studies on gasoline intoxication. Part I. Electroencephalographical changes and lead content in organs of rats administered lead-free and lead-containing brands of gasoline. Japanese Journal of Industrial Health, 14, 9-20.

Sanders, L. W. (1964). Tetraethyllead intoxication. Archives of Environmental Health, 8, 270-277.

Walker, G., and Boyd, P. R. (1952). Tetraethyl lead poisoning. Report of a non-fatal case. Lancet, 2, 467-469.

Yamaga, S., Saruta, K., Omori, K., Ueda, H., Oshima, R., and Nito, Y. (1959). A survey on tetraethyl lead poisoning during petroleum-tank-cleaning. Japanese Journal of Hygiene, 14, 852-857.

Received for publication December 1, 1972

Accepted for publication March 20, 1973 